\title{
Double skin façade: Modelling technique and influence of venetian blinds on the airflow and heat transfer
}

\author{
Draco Iyi, Reaz Hasan, Chris Underwood, Roger Penlington \\ Department of Mechanical and Construction Engineering, \\ Faculty of Engineering and Environment, Northumbria University, \\ Newcastle Upon Tyne, NE1 8ST, UK
}

\begin{abstract}
The demand to reduce building cooling load and annual energy consumption can be optimised with the use of Double Skin Facade (DSF). Computational Fluid Dynamics (CFD) methods are frequently used for the analysis of heat transfer through DSF. However, considerable uncertainty exists regarding few key parameters, such as modelling strategies and the solar heat transmitted to the indoor space as a function of the blind tilt angles and positioning within the façade channel. In this paper we have investigated four modelling strategies and the influence of blind tilt angle and their proximity to the façade walls. The DSF system used in this investigation is equipped with venetian blinds and facades that absorb and reflect the incident solar radiation and transfer the direct solar heat gain into the building. A finite volume dis- cretization method with the SIMPLE solution algorithm of the velocity-pressure coupling involving the low-turbulence kee model is used. A ray-traced solar model is coupled with long wave radiation model to solve the complete solar and radiation fields along with convection and conduction fields.
\end{abstract}

On the modelling strategies, three dimensional domains were cast over three computational zones; external zone with solar radiation entering the outer skin of glass; buoyancy-driven air cavity zone with convection and transmitted solar radiation; and an internal zone. Also investigated is the thermal behaviour of the DSF due to the blind tilt angles $\left(30^{\circ}, 45^{\circ}, 60^{\circ}\right.$, and $\left.75^{\circ}\right)$ and its position from the facade walls (104 mm, $195 \mathrm{~mm}, 287 \mathrm{~mm}$ and $379 \mathrm{~mm}$ ). Validations of the results are based on experimental data from the literature and the predicted trends compared very well with the experimental measurements. The heat gain due to direct solar radiation and convection through the facades to the internal space are presented. Comparative analysis of the four modelling strategies shows little variation of the results. The implication is a reduction in complexity and cost of modelling, since the additional effort requires in the CFD modelling is not justified by a significant improvement of the results. The variations of the blinds tilt angles as well as its 
proximity to façade walls significantly influences the convective flow within the façade cavity and the heat gains to the indoor space

\section{Introduction}

The potential to reduce building cooling load and annual energy consumption is widely recognized in the use of devices to control solar gain. Double-skin facades (DSF) are getting more and more attention and are widely used in commercial buildings. In hot summer and cold winter regions, a naturally ventilated external DSF with venetian blinds is the most common type, due to the simple control strategy and good energy performance, compared with mechanically ventilated DSF. In order to save air-conditioning energy and to guarantee indoor thermal comfort, the performance of shading, ventilation and heat transfer in naturally ventilated DSF buildings should be analyzed and optimized. Although the concept is not new, its complexity and adaptability to different climatic conditions increase the need for further careful analysis. The accuracy of numerical modelling of the flow and heat transfer predictions in the facade will lead to less uncertainty in the design and construction by better adapting to the performance requirements of the designer.

The objective of this study is to perform a detailed numerical model for the airflow and heat transfer phenomena in a DSF system by studying the influence of the location of the blinds and the slat angle on the temperature and air distribution in the air cavity and on the glass surfaces. Also investigated is the influence of numerical modelling strategies. This paper considered various parametric studies on DSF air flow and heat transfer. Firstly, a detailed numerical study was conducted to analysed different CFD modelling strategies involving the coupling different fluid zones and comparing the results, which aims to limit the cost and effort in the numerical modelling of the DSF. Secondly, comparative numerical analyses of the influence of venetian blind inclination and proximity on the heat transfer to the indoor space. The result of the research is an improved understanding of the thermal and air flow behaviour of such ventilated double skin facades

\section{DSF with blind}

The recent trend in the research community for the numerical modelling of flow and heat transfer in double skin facades is focused on facades with interaction of obstacles with the flow and heat transfer within the cavity. These obstacles are in the form of venetian blinds for solar shielding and building construction elements. Ji et al. [1], Mei et al. [2] , Safer et al. [3] and Ye et al. [4] conducted 2D numerical simulation to investigate coupled convective and radiative heat transfer through the DSF with venetian blinds inside the facade cavity. They investigated the influence of the blind angle in the range of $0-80^{\circ}$ on the air flow and heat transfer within the cavity and their modelling results were validated with the measurement from a section of facade tested within a solar simulator, and with predictions from a component based nodal model. Agreement between experiment and numerical results was generally good and any discrepancies were caused by the implication of the CFD model resulting in less turbulence mixing within the facade cavity. Their results have shown that the presence of the venetian blinds has led to 35 percent enhancement in natural ventilation flow and 75 percent reduction in heat loads for the internal environment and also the changes of the convective heat transfer coefficient on the glazing surfaces was caused by the venetian blinds with different angles.

Wilmer Pasut and Michele De Carli [5] of the University of California at Berkeley investigated the performance of the two most commonly used turbulence models (k- $\varepsilon$ and $k-\omega)$ for simulating the 
naturally ventilated DSF and results validated against experimental data from literature. Nassim et al. [6] conducted a comprehensive numerical modelling of radiative and convective heat transfer of a compact double-skin facade equipped with venetian blind and concluded that the convective heat transfer coefficients found were weak and only little influenced by slat tilt angles, but its effects on radiative heat transfer was very important, since it regulated the solar radiation transmitted to the inside. Fuliotto et al. [7] used a decoupling method to evaluate thermal performances and analysed fluid phenomena in a DSF. Solar radiation effects were evaluated with an analytical model, while complex flow and thermal effect were simulated using CFD. The numerical results agreed well with experimental data collected on a full scale test room with a ventilated DSF. Mei et al. [1] investigated the effects of external conditions, solar irradiation and exterior air temperature on double skin facade with differing internal characteristics. The effect of blind blade angle on cavity temperatures and air flow were reported.

Teshome et al. [8], investigated the airflow and heat transfer for a DSF system equipped with a venetian blind using the RNG turbulence model for a three-level combination of slat tilt angle and blind position. The prediction was validated using experimental data collected for a mechanically ventilated DSF equipped with venetian blinds. The predicted trends in glass and blind surface temperatures of the CFD model are compared well with the experimental measurements. Their results show that the presence of venetian blinds influences the surface heat transfer coefficients and the temperature and the air distribution in the DSF system. Also, the changes in the position of the blinds (outer, middle, and inner) have more effect on the distribution of temperature, velocity, and heat transfer compared to the changes in the slat angles $\left(0^{\circ}, 45^{\circ}, 90^{\circ}\right)$.

Wong et al. [9] investigated the effects of double glazed facade with ventilation system on the energy consumption, thermal comfort and condensation and compared results with a single glazed system. Their simulated results showed that double glazed facades with natural ventilation are able to minimize energy consumption as well as to enhance the thermal comfort, and that turning the mechanical fans on could also solve the condensation problem due to high humidity. Mona et al. [10], investigates the energy performance of a high-rise office building equipped with convectional insulated glazing using Energy Plus and CFD software Fluent to evaluate various thermal comfort parameters for the new configurations and their results show that the new configuration had a major impact on enhancing natural ventilation and hence a reduction in energy consumption.

\section{Model descriptions}

The DSF consists of a single outer glazing element; venetian blinds were situated at one-third of the facade. Solar heat flux is generated from a full-scale solar generator which is located at the front of the facade. The main dimensions of a double skin were taken from the experimental work of Mei et al. [11], as shown in Fig.1. The external environment dimensions are $3.8 \mathrm{~m}$ high by $0.6 \mathrm{~m}$ wide and $1.28 \mathrm{~m}$ depth. The outer skin of the facade is a single $12 \mathrm{~mm}$ thick clear glass pane. The external glass area is $1.28 \mathrm{~m}$ and $1.91 \mathrm{~m}$ high. Both the air intake and exhaust of the DSF are designed as a commercial grille arrangement to permit air flow through the cavity. The grilles are $0.24 \mathrm{~m}$ high and $1.45 \mathrm{~m}$ wide. Each grille (inclined at $30^{\circ}$ to the horizontal line) has three $0.045 \mathrm{~m}$ high spaces for air ingress and egress. The inner glass area is $1.28 \mathrm{~m}$ by $2.44 \mathrm{~m}$ high. The sun-shading blind is a Venetian type blind (solar-blockages). The blind blades are $80 \mathrm{~mm}$ wide and the blind is located at one third of the cavity width as measured from the outer skin of the external glaze. The cavity formed by the outer and inner layer is ventilated and frequently contained a blind. This blind, together with the cavity 
ventilation, provides a means to control the heat transfer across the facade, in terms of solar gain transmission and recovery of heat lost from the interior.

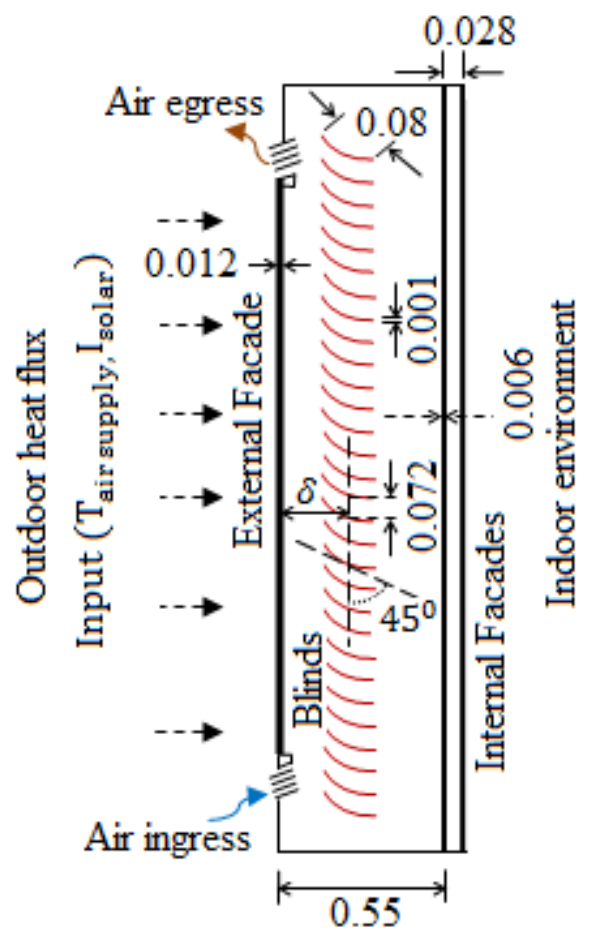

Figure 1: Schematic description of the model

Fig.1 gives the schematic of the facade with the external and the internal environment and the DSF ventilation pots (air ingress and egress). The cavity formed by the outer and inner layer is ventilated and frequently contained a blind. This blind, together with the cavity ventilation, provides a means to control the heat transfer across the facade, in terms of solar gain transmission and recovery of heat lost from the interior.

In his current study a numerical parametric studies are done for the heat transfer problem in order to fully describe the gain to the indoor space. The convective and long-wave radiation fluxes were modelled in addition to the transmitted solar flux. A parametric study was conducted to quantify the influence of several factors of the air flow and heat transfer by the DSF. The factors investigated are; Modelling strategies and Solar blockages (Solar blockages proximity from the external glazing and Solar blockages inclination angle from the vertical centre-line) and the effect of the solar-blockage angles and its positioning within the DSF channel on the airflow and thermal performances of the cavity and the indoor space is reported. The quantified values will serve as an outline and guidance to assist designers of such facades.

\section{DSF modelling strategies and solar blind inclination and proximity}

Several solution techniques exist for the numerical modelling of DSF system in the open literature. There seem to be no studies to evaluate the influence of the different modelling strategies based on coupling and/or decoupling of the external and/or internal environmental conditions with the DSF channel flow and heat transfer. This current study aims to resolve this uncertainty by quantifying the influence of different modelling approaches for the airflow and heat transfer. Four different cases of modelling strategies were considered as shown in Fig.2a-d. These are (a) coupling the flow from the 
external and internal environments - Case 1, (b) coupling the DSF flow with the external environment only - Case 2, (c) decoupling the DSF flow with the internal and external environments - Case 3 and (d) Coupling the DSF flow with the external environment only - Case 4. For simplicity, the outdoor environment wind speed is not considered. For the investigation into the influence of solar blockages inclination and proximity, the configuration used is that of the DSF cavity coupled with the internal environment (heat output) only. This arrangement was used for the studies because of our interest in evaluating some key parameter in the indoor environmental.

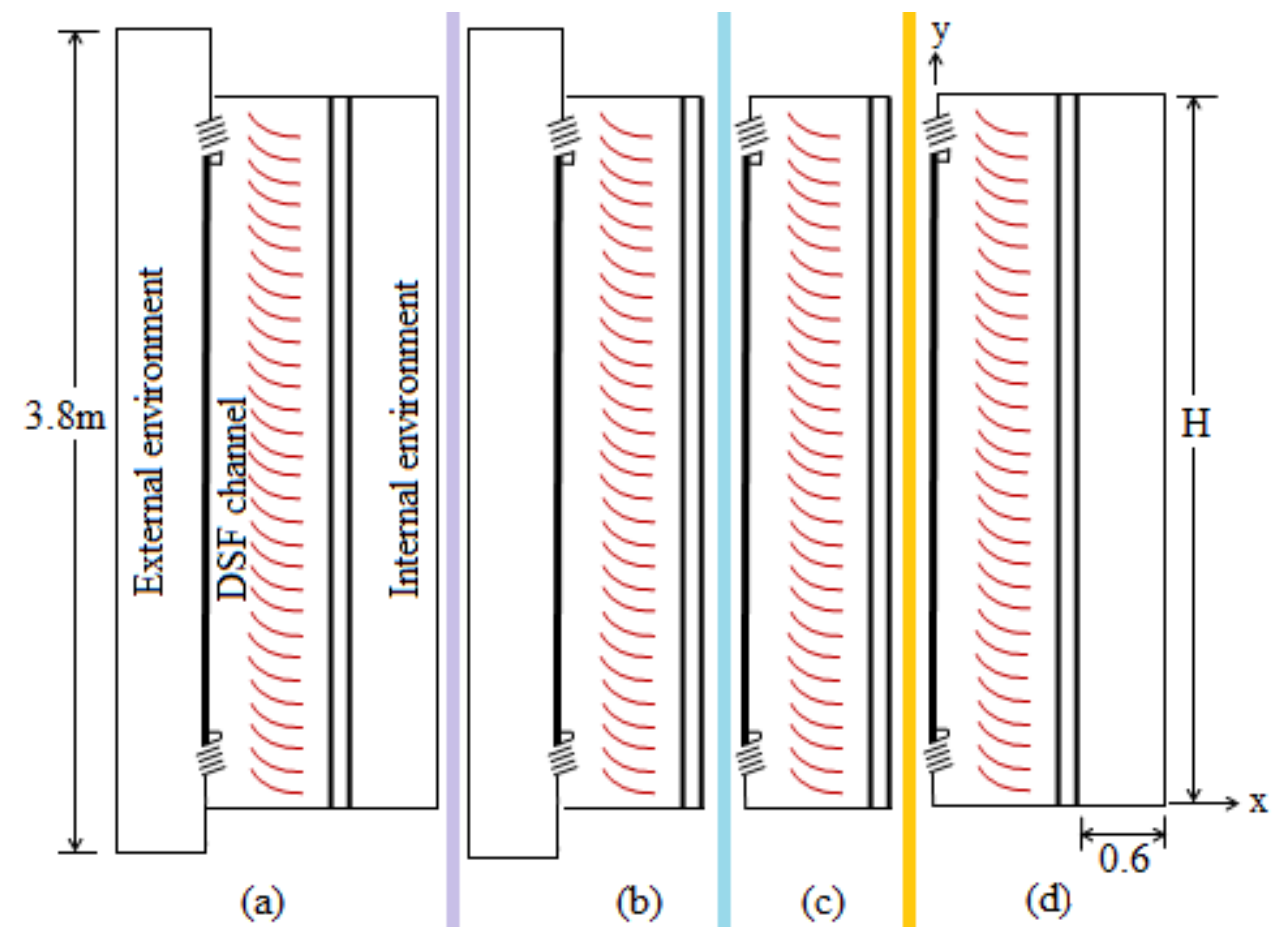

Figure 2: modelling geometrical cases (a) case 1 (b) case 2 (c) case 3 (d) case 4

The solar blockages inclination angles are very important, since they regulate the amount of radiation transmitted to the indoor space. Heat exchange between the glazing elements and the surrounding occurs by conduction, convection and radiation. It is important to quantify the airflow and thermal behaviour of the indoor environment due to varying blockages inclination angle. Further parametric study was conducted which is aimed at finding the optimal location of the solar blockages devices in order to achieve a high air flow within the DSF channel. If this can be guaranteed, the risk of an undesirable facade overheating can be avoided. It is assumed that the angles of inclination ( $\theta$ in Fig.1) which the solar-blockages make with the vertical axes can be adjusted to achieve a series of blockage inclination angles from the vertical centre-line $\left(15^{\circ}, 30^{\circ}, 45^{\circ}, 60^{\circ}\right.$ and $\left.75^{\circ}\right)$. Also the proximity of blinds, $\delta$ also shown in Fig.1, the external glazing can be varied for values of $0.104 \mathrm{~m}, 0.195 \mathrm{~m}$, $0.287 \mathrm{~m}, 0.379 \mathrm{~m}$ and $0.470 \mathrm{~m}$. The outdoor and indoor air temperature is fixed at $20^{\circ} \mathrm{C}$ and a fixed solar irradiance value of $715 \mathrm{~W} / \mathrm{m}^{2}$ was used in the simulation. The air flow and heat transfer of the facade system are evaluated at different positions and results compared.

\section{Numerical Methods}

In this section the issues of airflow and radiation modeling are discussed in some detail to highlight the specific matters in the context of DSF. The fundamental methodology and some of the governing equations are also discussed. A comprehensive numerical modelling of air flow and turbulence, solar radiation and convection heat transfer is carried out. 


\subsection{Airflow and thermal radiation modelling}

Calculations were carried out using the commercial CFD package FLUENT 14.0 which is part of the ANSYS [2011] software. The methodology involves the iterative solution of the Navier-Stokes equations along with continuity and energy equation using the SIMPLE algorithm on collocated variables within a structured-unstructured mesh configuration. Turbulence was modelled using the Launder-Sharma lowReynolds number of the k-epsilon model. In the 3D full scale coupled DSF model a non-uniform structured and unstructured mesh density of about 6million was used. Without going into detailed description of the governing differential equations which may be found in several text books such as Versteeg and Malalasekera [12] or FLUENT 14.0 manual, we concentrate on the numerical strategies and accuracy aspects of the predictions.

From numerical analysis point of view, the accuracy of computations is affected by the choice of grids, the viscous models, discretisation schemes and convergence and had been the major concern for numerical scientists [13-15]. These uncertainties that may influence the flow physics were carefully taken into account in the numerical modelling for greater accuracy. For discretisation of the convection terms, second order convection schemes have been followed. Utmost care has been taken to address the issue of grid density and grid quality. The mesh was made up of structured quad mesh near the walls and unstructured near the core region where the flow velocity is very low. In order to capture the sharp gradients the mesh was clustered near the walls where a minimum mesh orthogonal quality is about 1 (value close to zero indicates low quality mesh and value close to one indicates high quality mesh).

Particular attention was given to resolve the boundary layer very close to the walls because the low-Re turbulence models have been used for the simulations. The number of cells in the first layer of each blind was initially 40 which was then raised to 68 corresponding to an overall mesh density of 90,500 . The results were fairly insensitive to the changes of grid density around the solar blinds, and hence all the calculations reported in this paper were obtained with this mesh. The value of the non-dimensional distance $\mathrm{y}^{+}$for the final mesh was found to be just below 1 for all surfaces (cavity and solid obstacles) justifying our use of the low-Re model. It is worthwhile to note that the process of computing a steadystate solution using very fine mesh has been quite challenging because of the oscillations associated with higher-order discretisation schemes. As a result, a number of steps were taken to achieve a steady-state solution. Initially, a lower value of Rayleigh number $\left(10^{7}\right)$ was adopted to start the solution with the firstorder scheme and the solution was allowed to run to convergence which was typically three orders of magnitude lower than the residual at the start. The resulting data file was then used as an initial guess for the higher Rayleigh number (greater than $10^{9}$ ) simulation using the higher-order discretization scheme. This method helped to create a more realistic initial field for the low-Re $k-\varepsilon$ run.

The energy and the radiation equation were decoupled from the momentum equation and were solved first. When the temperature on the components developed sufficiently, the flow equations were then solved together with the radiation equation and iterated to convergence. The large difference in the thermal conductivity between the air and the aluminium blinds may result in numerical round-off error, which caused global imbalances of energy as oscillation. Therefore, the simulation was run in double-precision to overcome this problem. Calculations were performed using a single Intel core 2Duo E6600 $2.4 \mathrm{GHz}$ processor and a typical run took about 48 hours of computing time. The UnderRelaxation parameters and the discretization scheme used in the simulations are presented in Table 1: 
Table 1: Summary of solver parameters

\begin{tabular}{lll}
\hline Parameters & URF & Discretization \\
\hline Pressure & 0.3 & PRESTO! \\
Density & 1 & - \\
Body force & 1 & - \\
Momentum & 0.3 & Second Order Upwind \\
Turbulence kinetic energy & 0.5 & Second Order Upwind \\
Turbulence dissipation rate & 0.5 & Second Order Upwind \\
Turbulent viscosity & 0.8 & Second Order Upwind \\
Energy & 0.9 & Second Order Upwind \\
Discrete ordinates & 0.8 & Second Order Upwind \\
\hline
\end{tabular}

Finally, to simulate the heat transfer due to radiation, Discrete Ordinate Method [16-18] has been chosen due to its proven superiority in predicting radiative heat transfer involving a participating medium. In this study, the general equation of heat transfer by radiation (in a given $\vec{s}$ direction) for both un-humidified and humidified cavity is:

$\vec{\nabla} \cdot(I(\vec{r}, \vec{s}) \vec{s})=0$

Where $I(\vec{r}, \vec{s})$ is the radiative intensity in $\vec{s}$ direction and $\vec{r}$ the position vector. At the surface of the blinds, thermal boundary condition is:

$-\lambda \vec{\nabla} T \cdot \vec{n}+\emptyset_{\text {net } \cdot r a d}=-\lambda \vec{\nabla} T_{p} \cdot \vec{n}$

Where $\emptyset_{\text {net.rad }}=\emptyset_{\text {in }}-\emptyset_{\text {out }}$,

$\emptyset_{\text {in }}=\int_{\overrightarrow{\mathrm{s}} \cdot \vec{n}>0} I_{i n} \cdot \vec{S} \cdot \vec{n} \cdot \mathrm{d} \Omega$,

$\emptyset_{\text {out }}=\left(1-\varepsilon_{r}\right) . \emptyset_{\text {in }}+\varepsilon_{r} \sigma T_{p}^{4}$.

All calculations are done with a steady state formulation of the numeric solver, as additional transient investigations did not achieve higher accuracy. The angular discretization used in the DO modelling for the localized heat source is $6 \times 6$ divisions. A sensitivity study of the angular discretization was performed by starting with $2 \times 2$, then $4 \times 4$, and so forth until there is no considerable change in maximum temperature at $6 \times 6$ divisions.

\subsection{Solar irradiation modeling}

Only direct solar radiation is considered in the CFD model as the diffuse effects were expected to be negligible. The Rayleigh numbers based on the channel height for the two cases investigated are in the order of $10^{9}$ to $10^{10}$ which is within the range of low turbulent flow. The primary input data are the outdoor/indoor air temperature, solar irradiation from the solar generator and heat transfer coefficient of the facade walls.

Solar ray tracing options of the solar load model [19] (FLUENT 14.0) were employed to calculate radiation effects that enter the computational domain. The ray tracing approach is highly efficient and a practical means of applying solar loads as heat sources in the energy equations and it provides a practical tool for determining the solar heating effect inside a building. The solar load model of the ray tracing algorithm is used to predict the direct illumination energy source that results from incident solar radiation. It takes a beam that is modelled using the incident solar radiation position vector and 
illumination parameters and applies it to any or all wall or inlet/outlet boundary zones, performs a face-by-face shading analysis to determine well-defined shadows on all boundary faces and interior walls, and computes the heat flux on the boundary faces that results from the incident radiation.

Solar Ray Tracing is not a participating radiation model. It does not deal with emission from the surfaces. The reflecting component of the primary incident load is distributed uniformly across all surfaces rather than being local to the surfaces reflected to. Surface emission is an important factor in our study; therefore we implement a radiation model (Discrete Ordinates method) in conjunction with the Solar Ray Tracing. The discrete radiation model is coupled with the solar ray tracing model to deal with emission from surfaces, and the reflecting component of the primary incident load through the computational domain.

Direct solar irradiation from a solar generator is transmitted by radiation and some by natural convection through the glazing elements of the DSF to the temperature controlled internal environment located behind the inner glazing. Some of the radiation emitted by the solar simulator is transmitted through the glazing elements, while some is reflected and some is absorbed. Since radiation is the dominant mode of heat transfer in the computational domain, therefore, the flow iterations per radiation iteration are specified as 5. In order to obtain the temperature profile at the glass wall, FLUENT uses a differential energy balance equation to determine the conductive heat flux. The heat transfer equation for the differential element of the glass wall in two dimensions is given by;

$\frac{\partial}{\partial x}\left[\frac{k_{g}}{C p_{g}} \frac{\partial T_{g}}{\partial x}\right]+\frac{\partial}{\partial y}\left[\frac{k_{g}}{C p_{g}} \frac{\partial T_{g}}{\partial y}\right]+\frac{1}{C p_{g}} \frac{d \emptyset}{d x}=0$

Where $\varnothing$ is the attenuation energy function by absorption and scattering, which depends on the extinction coefficient $\left(s_{g}\right)$ as shown as [20]:

$\varnothing(x)=I \exp \left[-s_{g}\left(L_{g}-x\right)\right]$

Where ' $\mathrm{I}$ ' is the solar radiation, $\mathrm{L}$ is the thickness of the glass.

The boundary condition for the glass walls is expressed as, $\left[\mathrm{x}=\mathrm{W}+\mathrm{L}_{\mathrm{g}}\right]$ :

$-k_{g} \frac{\partial T_{g}}{\partial x}=h_{e x t}\left[T_{g}-T_{a m b}\right]+\sigma \varepsilon_{g}^{*}\left[T_{g}^{4}-T_{a m b}^{4}\right]$

Where $T_{a m b}$ is the outdoor ambient are temperature.

Fig. 3 show the schematic of the heat transfer analysis 


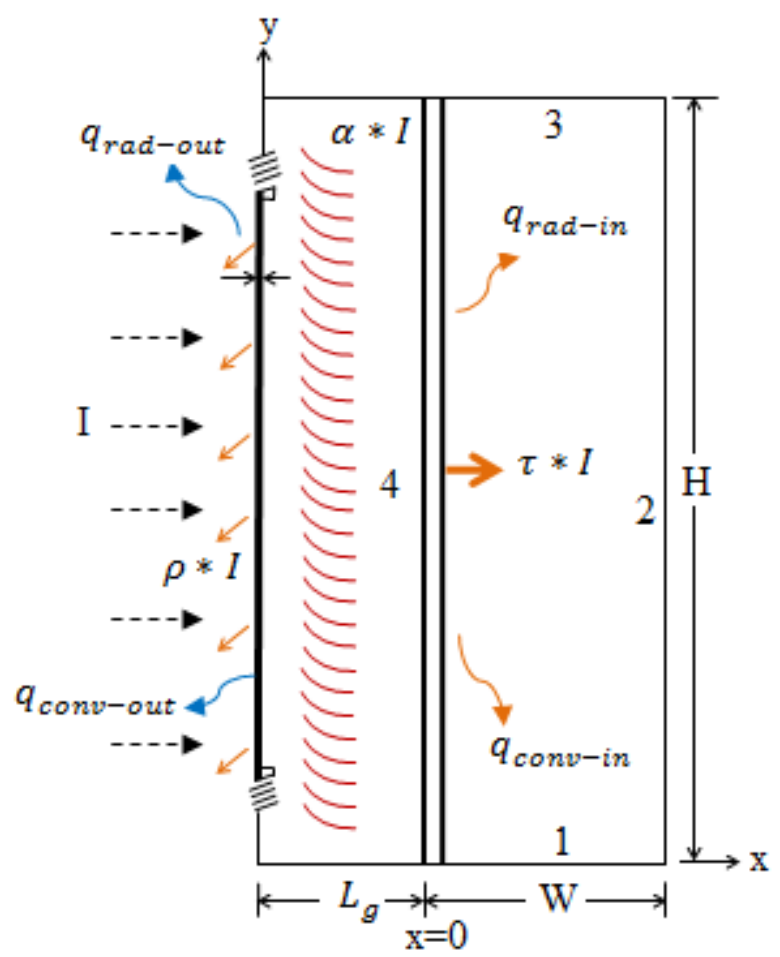

Figure 3: Schematic representation of the heat transfer analysis

The velocity boundary conditions on the walls are zero and temperature boundary conditions are set as: Bottom adiabatic wall (wall 1): $q_{\text {cond-1 }}=-q_{\text {rad-1 }}$

Isothermal vertical wall (wall 2): $T(0, y, t)=T_{2}$

Top adiabatic wall (wall 3): $q_{\text {cond }-3}=-q_{\text {rad-3 }}$

Glass vertical wall (wall 4): $q_{\text {cond-g-4 }}=q_{\text {cond }-4}+q_{\text {rad }-4}$

Where $q_{\text {cond-1 }}, q_{\text {cond-3 }}$ and $q_{\text {cond-4 }}$ are the conduction heat fluxes for wall 1, 3 and 4 respectively.

\subsection{Numerical modeling parameters}

The materials used for the simulations are transparent media (air), semi-transparent solids (glazing) and opaque solids (venetian blinds). The key parameters of these materials for air flow and heat transfer are shown in Tables 2 and 3. The air density is set as a function of temperature using the Boussinesq approximation method. This method treats density as a constant value in all solved equations, except for the buoyancy term in the momentum equation.

Table 2: Thermo-physical properties of air at $20^{\circ} \mathrm{C}$

\begin{tabular}{ll}
\hline Property & Dry-air at $20^{\circ} \mathrm{C}$ \\
\hline Density $\left(\mathrm{kg} / \mathrm{m}^{3}\right)$ & 1.2047 \\
Specific heat $(\mathrm{J} / \mathrm{kg}-\mathrm{K})$ & 1006.1 \\
Thermal conductivity $(\mathrm{w} / \mathrm{m}-)$ & 0.0256 \\
Absorption coefficient $(1 / \mathrm{m})$ & 0.01 \\
Refractive index & 1 \\
\hline
\end{tabular}




\begin{tabular}{ll}
\hline Dynamic Viscosity $(\mathrm{kg} / \mathrm{m}-\mathrm{s})$ & $1.821 \times 10^{-5}$ \\
Thermal diffusivity $\left(\mathrm{m}^{2} / \mathrm{s}\right)$ & $2.112 \times 10^{-5}$ \\
Thermal expansion coefficient $(1 / \mathrm{K})$ & $3.411 \times 10^{-3}$ \\
Prandtl number & 0.7156 \\
\hline
\end{tabular}

Table 3: Thermo-physical properties of the material used in the simulations

\begin{tabular}{|c|c|c|c|c|}
\hline Property & $\begin{array}{l}\text { Single } \\
\text { glazing }\end{array}$ & $\begin{array}{l}\text { Double } \\
\text { glazing }\end{array}$ & $\begin{array}{l}\text { Venetian } \\
\text { blinds }\end{array}$ & $\begin{array}{l}\text { Passive } \\
\text { walls }\end{array}$ \\
\hline Density $\left(\mathrm{kg} / \mathrm{m}^{3}\right)$ & 2500 & 2500 & 2719 & 10 \\
\hline Specific heat $(\mathrm{J} / \mathrm{kg}-\mathrm{k})$ & 840 & 840 & 871 & 830 \\
\hline $\begin{array}{l}\text { Thermal conductivity (w/m- } \\
\text { k) }\end{array}$ & 1.7 & 1.7 & 202.4 & 0.1 \\
\hline Absorption coefficient $(1 / \mathrm{m})$ & $30^{*}, 3000^{*}$ & $\begin{array}{l}30^{*}, 1285.7^{*} \\
*\end{array}$ & - & - \\
\hline Refractive index & 1.5 & 1.5 & 1.44 & 1 \\
\hline Emissivity & 0.84 & 0.84 & 0.7 & 0.58 \\
\hline
\end{tabular}

The external glazing element whose outer surface is exposed to ambient air is modelled as an internal wall with cells on both sides, so that there is also a shadow zone corresponding to it. The shadow is facing the fluid zone. The inner and the outer surface of the glazing elements are set to semitransparent conditions. This allows radiation to be transmitted through the wall between the adjacent participating cell zones. It also calculates the effect of reflection and refraction at the interface. These effects occur because of the change in refractive index (set through the material properties) and are a function of the incident angle of the radiation and the surface finish. In our case, the glazing element is assumed to have a very smooth surface so the diffuse fraction is set to 0 .

The DFS cooling mechanism on the outer surface of the glaze is by natural convection and radiation. The convective heat transfer is taken as $25 \mathrm{~W} / \mathrm{m}^{2} \mathrm{k}$ following BBRI, 2002 [21]. It is worthwhile to mention that the effect of environmental condition and wind speed can be partially modelled via the heat transfer coefficient

\subsection{Boundary conditions}

In the computational domain, glazing elements are modelled as semi-transparent solids and venetian blinds as opaque solids. The semi-transparent glazing elements are spectrum selective of radiation transfer, i.e., short wave radiation (solar) has a very high transmittance while long wave (thermal) radiation has a very low transmittance. These have been modelled using a 'two-band' spectrum model (ANSYS FUENT-14). The solar band corresponds to wavelengths smaller than 2.7 micrometers, and the thermal band to wavelength larger than 2.7 micrometers. All glazing materials are considered as participating in radiation, which enables transmission and absorption of radiation inside the DSF.

The surface of the external glazing element is mainly cooled by natural convection to the surrounding. As these walls are transparent it must also lose radiation to the surroundings, while the surroundings will supply a small source of background radiation associated with the temperature. Therefore a mixed thermal condition was applied to provide the source of background radiation as well as to calculate the convective cooling on the external glazing. The source of the background radiation is added directly to the discrete ordinate (DO) radiation equation. The background radiation was 
supplied from the thermal conditions. An external emissivity of 1 is used, in keeping with the assumption of a small object in a large enclosure [22]. For a semi-transparent wall the internal emissivity has no effect as there is no absorption or emission of the surface.

It is assumed that the glazing elements are clean and there are no particles in the air to scatter the radiation in different directions, the scattering coefficient is set to zero (assuming zero humidity). Conduction in the solar blockage thickness $(0.001 \mathrm{~m})$ is modelled as a thin wall by using the shell conduction thermal condition and with the help of text user interface to achieve robustness; the command ignores the secondary gradient for highly skewed shell conduction cells. This allows the solver to grow layers of prism to model conduction in the planar direction according to the specified thickness. The absorptivity and transmissivity of all glazing and opaque material is given the Table 4 . This applies to the long wave (infrared) and short wave (visible) bands. These radiant properties are obtained from ASHRAE fundamentals handbook 2010 [52]. The spectral transmission and absorption behaviour of glass was considered in the definition of material properties and especially in the implementation of the radiation model. Glass has a high transparency for visible light, but it is nearly impermeable for infrared radiation with a wavelength beyond 2.5 micrometers.

Table 4: Solar radiance properties of materials used

\begin{tabular}{ll}
\hline Surface & Radiant properties \\
\hline External glass & $\alpha_{\mathrm{v}}=0.09, \alpha_{\mathrm{IR}}=0.09, \alpha_{\mathrm{D}}=0.1$ \\
& $\tau_{\mathrm{v}}=0.83, \tau_{\mathrm{IR}}=0.83, \tau_{\mathrm{D}}=0.75$ \\
Internal glass & $\alpha_{\mathrm{v}}=0.49, \alpha_{\mathrm{IR}}=0.49, \alpha_{\mathrm{D}}=0.49$ \\
& $\tau_{\mathrm{v}}=0.3, \tau_{\mathrm{IR}}=0.3, \tau_{\mathrm{D}}=0.32$ \\
Venetian blind & $\alpha_{\mathrm{v}}=0.5, \alpha_{\mathrm{IR}}=0.75$ \\
\hline
\end{tabular}

Were, $\alpha$ represents absorptivity $\tau$ represents transmissivity. The transcripts $\mathrm{v}$, IR and D represents visible, infrared and diffuse hemispherical components respectively.

The external wall is exchanging heat with a convection coefficient, $\mathrm{h}$, chosen according to the European standards for building design [51]: the convective heat transfer coefficient of the external glazing is $25 \mathrm{~W} / \mathrm{m}^{2}-\mathrm{k}$, and that of the internal glazing is $7.7 \mathrm{~W} / \mathrm{m}^{2}-\mathrm{k}$. The external and internal temperatures are both fixed at $20^{\circ} \mathrm{C}$. The upper and lateral walls are considered adiabatic and they do not participate in the solar ray tracing. The boundary of the air ingress and egress are modelled as a pressure inlet and pressure outlet with the same gauge total pressure of 0 , and in order to improve the result quality an angle the same as the ingress grille angle $\left(30^{\circ}\right)$ was used for the air direction in the ingress boundary condition. For the modelling strategies study, the boundary condition used for the external and internal boundaries are represented in Fig.4. 


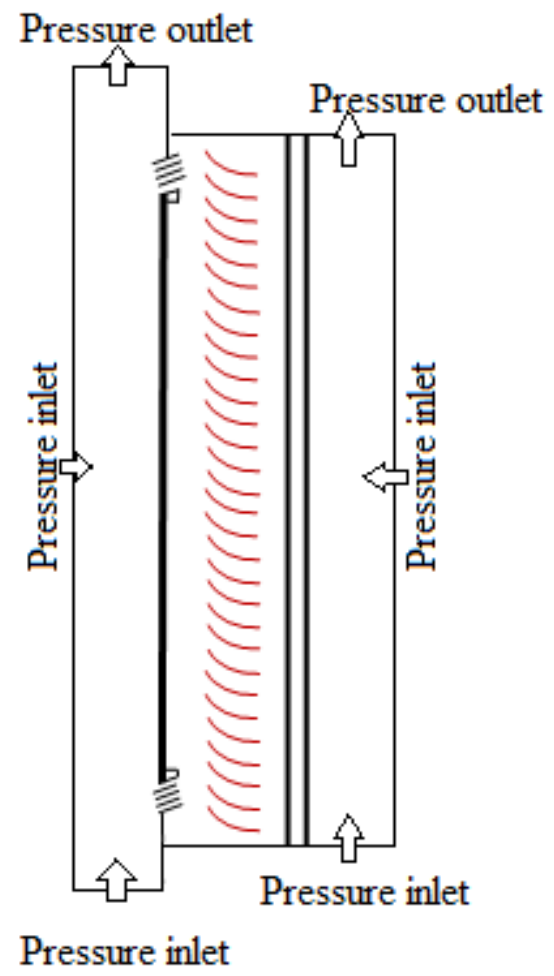

Figure 4: schematic of the boundary conditions for the internal and external environment boundaries

\subsection{Thermal parameters}

The total heat transfer across the glass wall is given by the Nusselt numbers. The total heat transfer involves the contribution of the convective and radiative Nusselt numbers which can be expressed as:

$N u_{\text {total }}=N u_{\text {conv }}+N u_{\text {rad }}$

Where:

$N u_{\text {conv }}=\frac{k}{q_{\text {cond }}} \int_{0}^{H} \frac{\partial T}{\partial x} d y$

$N u_{\text {rad }}=\frac{1}{q_{\text {cond }}} \int_{0}^{H} q_{\text {rad }} d y$

$q_{\text {cond }}=\frac{k_{a}\left(T_{4}-T_{2}\right)}{W}$

Where $T_{4}$ is the average temperature on the inner surface of the glass wall.

\subsection{Validation of the numerical model}

The numerical methodology presented above has earlier been validated for natural convection in cavities partially filled with disconnected blockages and the results were presented. The methodology showed good agreement for velocity, temperature and $\mathrm{Nu}$ against the experimental data of Laguerre (2009) and were presented earlier (Draco et al. 2012; 2013). Sensitivity of the flow to various turbulence models have been documented and the importance of low temperature radiation from 
surfaces were modeled with the DO model. The difference in the present paper is that we have also implemented the short wave solar radiation by solar ray tracing as mentioned before. Typical comparisons for temperature and velocity are shown in Fig. $\mathrm{xx}$ below. Our comparisons do indicate accurate trends but shows some difference which is comparable to others reported elsewhere (Pasut et al. 2012).
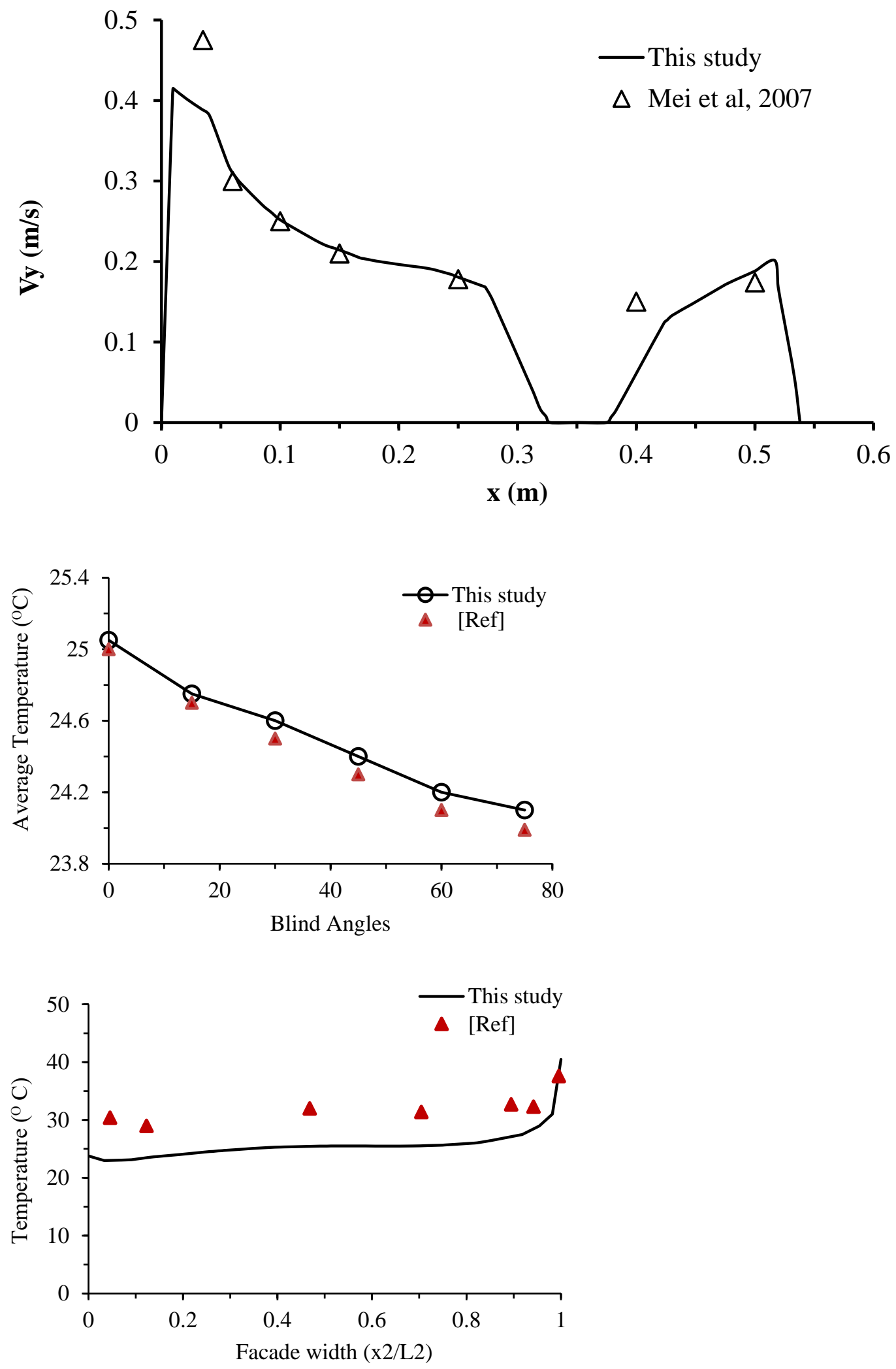


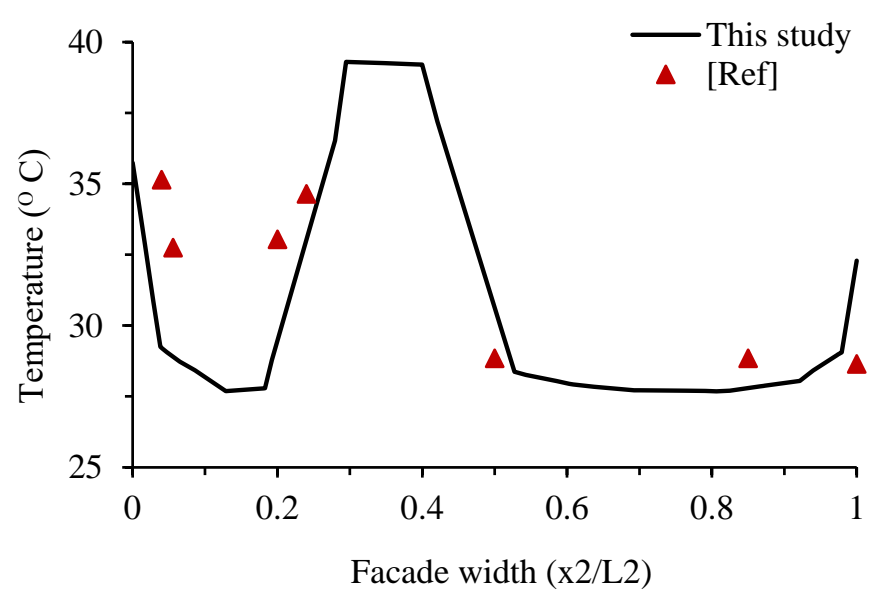

\section{Results and discussions}

Fig. 5 shows the schematic where all parameters were evaluated. Convective and solar heat transfer were evaluated at the internal glazed $(1 \& 2)$ and indoor wall surfaces. The domain widths are the outdoor (x1), DSF channel (x2) and indoor domain ( $\mathrm{x} 3$ and $\mathrm{x} 4)$. The horizontal temperature profile near the top wall of the indoor space was also compared for different parametric study. "Y" represents vertical line at mid-width of the indoor fluid domain. The solar flux field has also been presented for the investigation of the influence of a solar blind on heat transfer. Numerical results for the geometrical modelling strategies have been presented first followed by the results on solar irradiation. Solar blind positioning and inclination angle within the DSF channel are then presented, along with variation of outdoor air temperature.

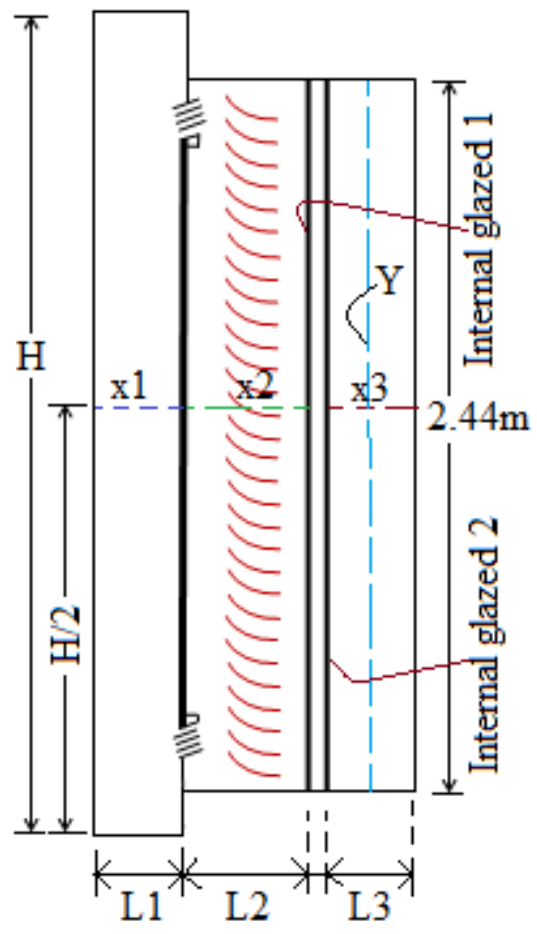

Figure 5: Schematic showing lines along the central plane were parameters are evaluated 


\subsection{Modeling strategies}

As stated earlier, the modelling approach cases used in this study are: Case 1 (outdoor + DSF channel + Indoor fluid zone), Case 2 (DSF channel + outdoor fluid zone only), Case 3 (DSF channel fluid zone only) and Case 4 (DSF channel and the indoor fluid zone only). The mesh density and computational effect are presented in Table 5.

Table 5: Computational efforts for all modelling strategies studied

\begin{tabular}{lcc}
\hline Cases & Number of cells & $\begin{array}{l}\text { Time (hours) to reach } \\
\text { converged solution }\end{array}$ \\
\hline Case 1 & $4,000,000$ & 96 \\
Case 2 & $5,000,000$ & 120 \\
Case 3 & $5,000,000$ & 120 \\
Case 4 & $6,000,000$ & I 44 \\
\hline
\end{tabular}

The predicted temperatures are plotted in Figs.6a-d along chosen lines x1, x2, x3, x4 and $\mathrm{Y}$ as shown in Fig.5.

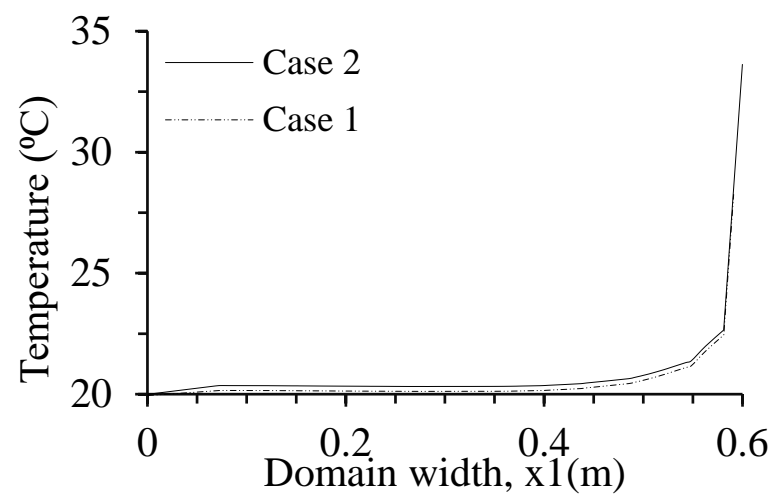

(6a)

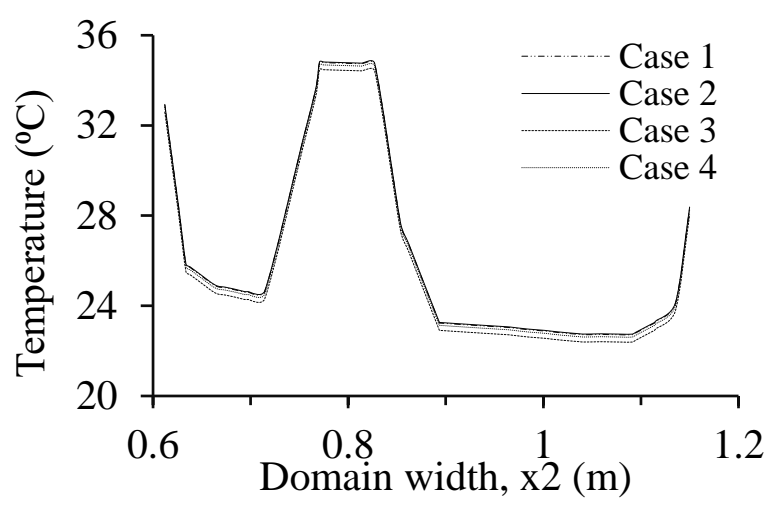

(6b) 


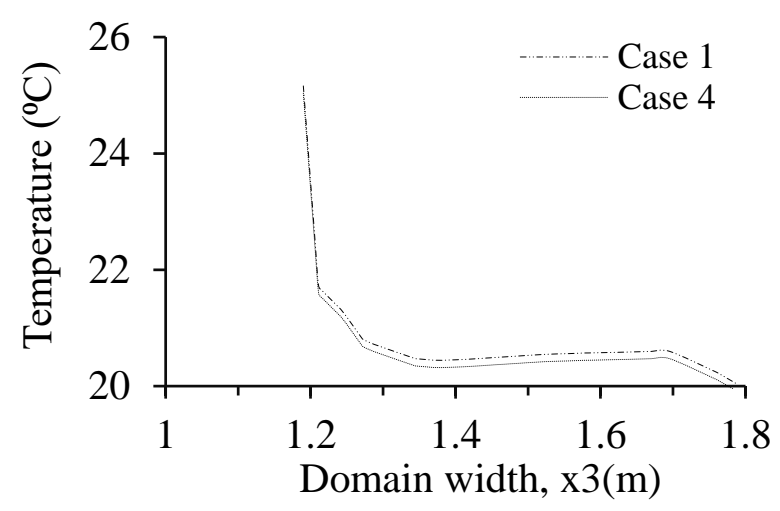

$(6 c)$

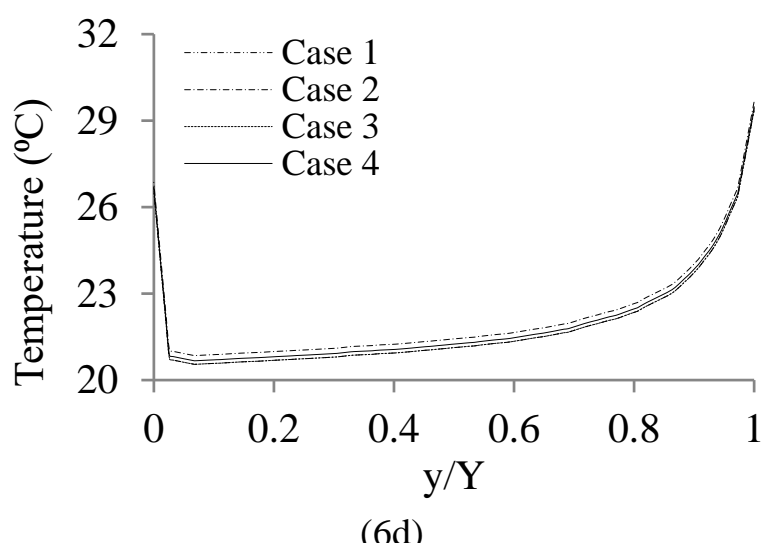

Figure 6: Temperature profile at (a) at mid-height of the indoor environment (b) mid-height of the DSF channel (c) mid-height of the indoor environment (d) mid-width of the DSF channel (=H/2)

Table 6: Average surface heat flux

\begin{tabular}{lllll}
\hline & \multicolumn{4}{l}{ Average Wall Heat Flux $\left(\mathrm{W} / \mathrm{m}^{2}\right)$} \\
\hline Surface & Case 1 & Case 2 & Case 3 & Case 4 \\
Internal glaze 1 & 40.7 & 40.59 & 40.88 & 41.01 \\
Internal glaze 2 & 35.61 & 35.97 & 35.69 & 35.74
\end{tabular}

Table 7: Average solar heat flux

\begin{tabular}{l|llll}
\hline Surface & \multicolumn{4}{|c}{ Average Solar Heat Flux $\left(\mathrm{W} / \mathrm{m}^{2}\right)$} \\
\hline & Case 1 & Case & Case 3 & Case 4 \\
& \multicolumn{4}{|c}{2} \\
Internal glaze 1 & 61.03 & 60.9 & 60.88 & 60.57 \\
Internal glaze 2 & 32.85 & 32.66 & 33.14 & 32.91 \\
\hline
\end{tabular}

Fig.6b shows the temperature profiles at the mid-height of the DSF cavity for all four cases tested; it can be observed that the maximum average temperature difference between all cases is about $0.4^{\circ} \mathrm{C}$. Also, the temperature profile at the indoor environment (case 1 and 4) measured at the mid-height is presented in Fig.6c and that at the external environment (case 1 and 2) shown in Fig.6a again shows no significant temperature difference between the cases. Finally, Fig.6d shows the temperature profile measured at the mid-width of the DSF channel for all cases and Tables 6 and 7 show the average wall 
and solar heat fluxes at the double-glazing and internal glazed-1 is facing the DSF channel zone and internal glazed-2 facing the indoor zone respectively. It is observed that the relative difference in the results is not very significant compared to the average temperature and heat fluxes (wall and solar).

Therefore, for all four modelling strategies employed in the study, there appears to be no significant difference in the key parameters responsible for the heat transfer which eventually determine the performance of the DSF, provided all indoor and outdoor boundary conditions are determined accurately. However, inclusion of external and internal environments can be useful if there is a need to investigate the behaviour of these environments. But, it will be less cost effective and also save computational effort by not including these domains in computations if the primary need is to numerically model the DSF channel only as is evident from Table 5. It is also clear that case-1 allows freedom in simulating complex environment scenarios.

\subsection{Influence of solar blind positioning from the external facade}

In this section, different blockage locations have been modelled and results presented and analysed. The distance between the solar blockage and the external glazing element ( $\delta$ in Fig. 1 ) was varied from $0.104 \mathrm{~m}$ to $0.379 \mathrm{~m}$. The total solar transmission is relatively unaffected by the changes in the blind position within the DSF channel. However, the scattering effect of the solar blockages relative to its location in the glazing/shading array can become important. The results presented in Figs.7-10 shown that at certain distance from the external glazing in the DSF channel, the temperature and heat transfer to the internal environment can be maximized. Therefore, optimised DSF channel ventilation can be achieved if the solar blind is located at about $0.195 \mathrm{~m}$ from the external facade. With this configuration, slightly higher air flow rates in the facade channel can be obtained as can be seen in Fig.10. Also, high air temperatures appear between the solar blockage and external facade. The heating of the solar blockages element is the driving mechanism for the DSF channel ventilation, air flow rate through the channel will rise with increasing irradiation. Thus, it is possible to transfer heat of up to $19 \%$ of the incident solar irradiation. This effect is shown in the plots of the local temperature and heat transfer as a function of $\delta$ values (Figs.9a- b). The final effect is evident through the temperature difference between the DSF channel and the internal environment as shown in Figs.7a.

Turbulent kinetic energy profiles are shown in Fig.9, demonstrating that turbulence is generally suppressed due to the blockage proximity. For the case where the solar-blockages are much closer to the glazing layers the heat transfer is enhanced. This is believed to be due to the location of the blockages closer to the glazing surface which means that the turbulent boundary layer caused by the blockages is sufficiently thin so that it overlaps with the thermal boundary layer of the glazing surfaces.

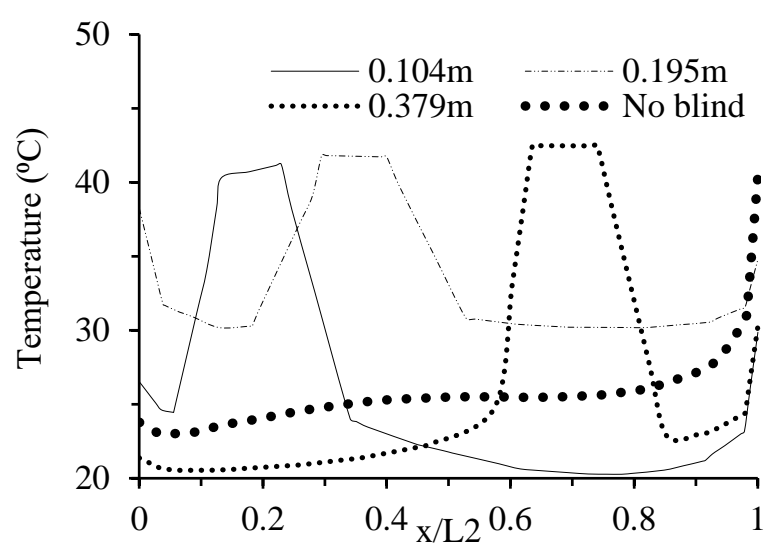


(7a)

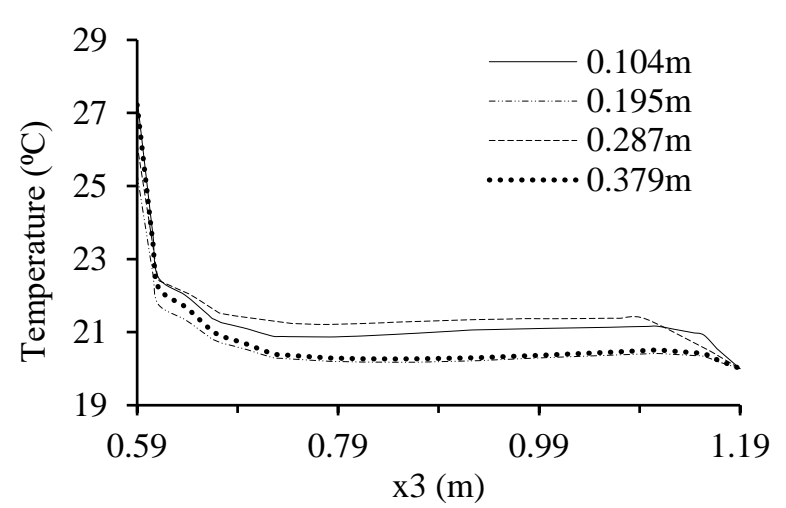

(7b)

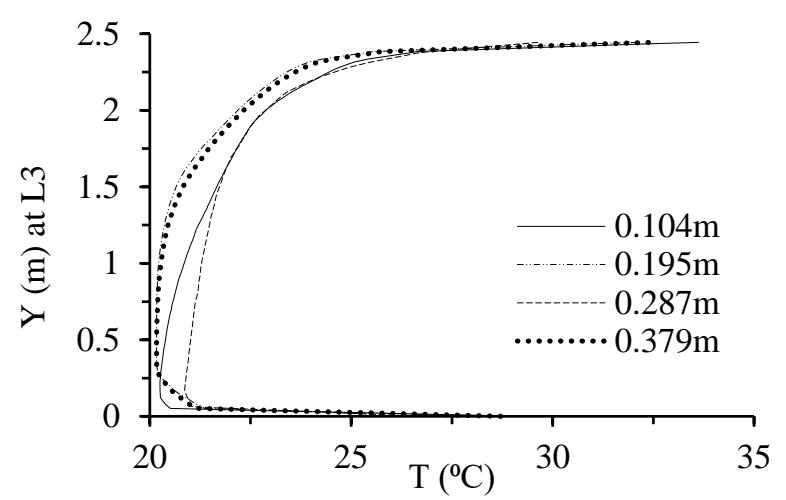

(7c)

Figure 7: Temperature profile at (a) mid-height of DSF channel (b) mid-height of the indoor environment (c) mid-width of the indoor environment, L3.

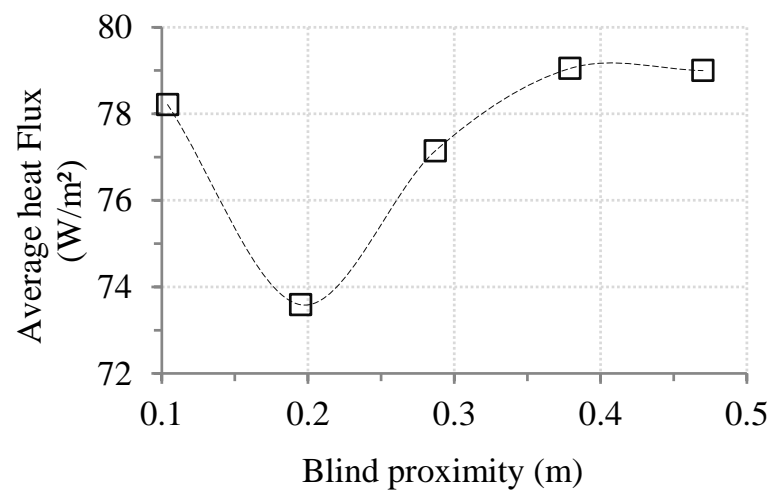

(9a) 


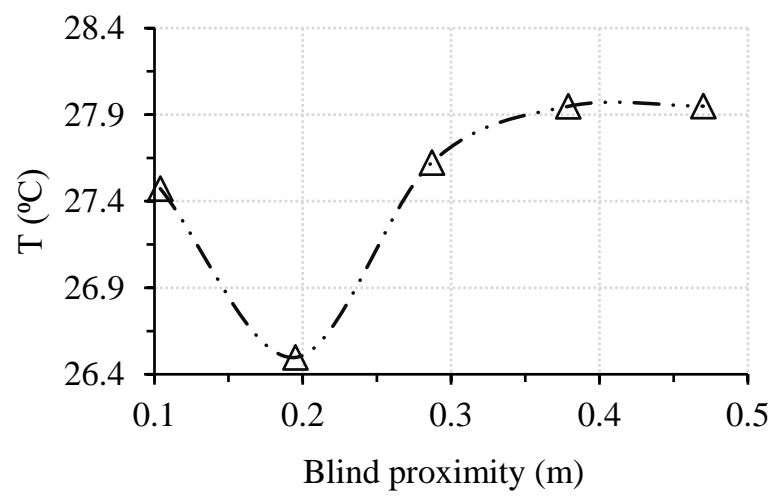

(9b)

Figure 8: (a) Average surface heat flux at indoor wall (b) average temperature at the internal glaze-2

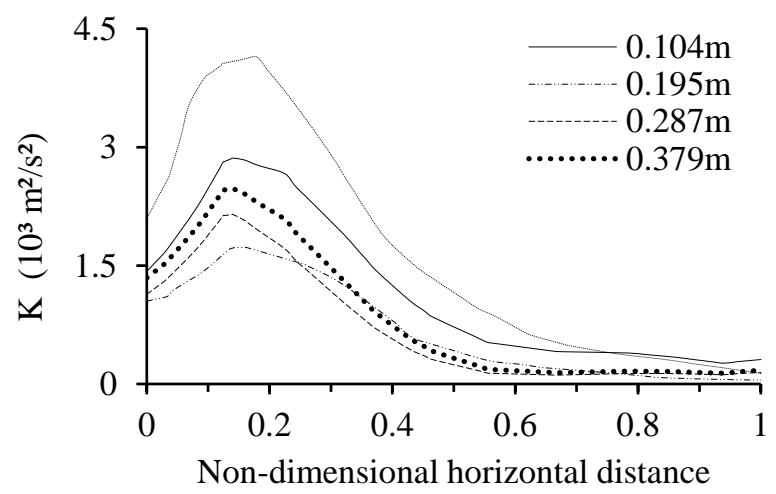

Figure 9: Turbulent kinetic energy profile measured at mid-height of the indoor environment

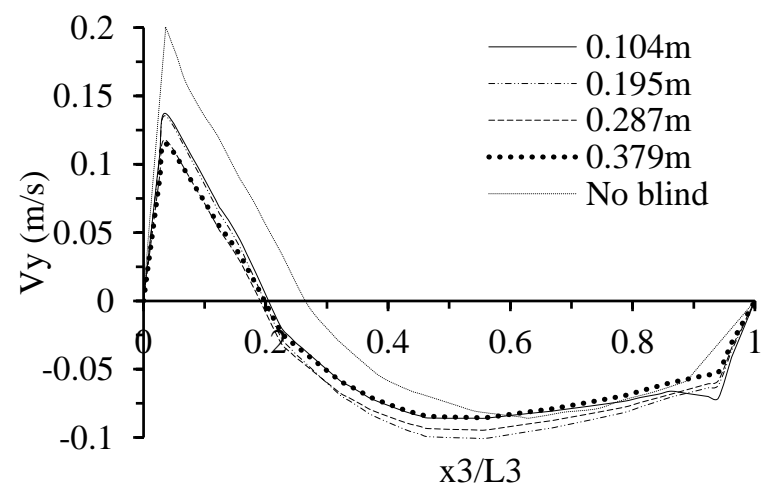

Figure 10: Vertical velocity profile at mid-height of the indoor environment

\subsection{Influence of solar blind inclination angle}

The ability to quantify both solar and thermal aspects of energy transfer in glazing/blockage systems allows us to investigate the effects of solar blockage inclination angles on the different components. Calculations were carried out for a fixed solar irradiance of $715 \mathrm{~W} / \mathrm{m}^{2}$ and the thermal condition of indoor and outdoor environment were both fixed at $20^{\circ} \mathrm{C}$. The solar blockages as shown in Fig. 1 were set at $30^{\circ}, 45^{\circ}, 60^{\circ}$ and $75^{\circ}$, where $30^{\circ}$ and $75^{\circ}$ relate to almost fully closed and almost fully opened respectively. The thermal behaviour of the indoor environment as a result of varying the solar blockage angle is presented in Figs.11-15 and the average values of heat flux and temperature are shown in Table 8-8. 


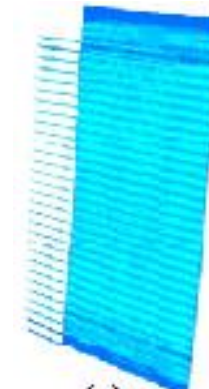

(a)

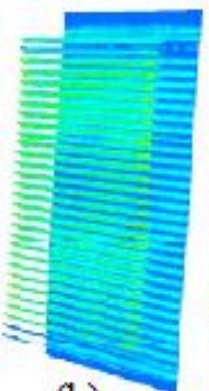

(b)

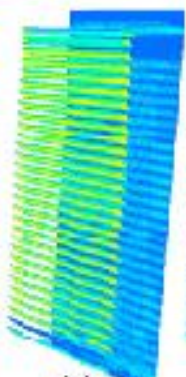

(c)

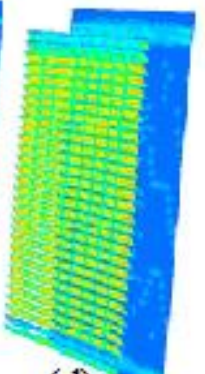

(d)

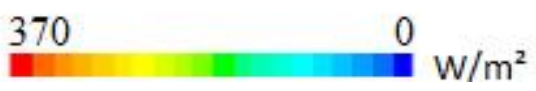

(11a)

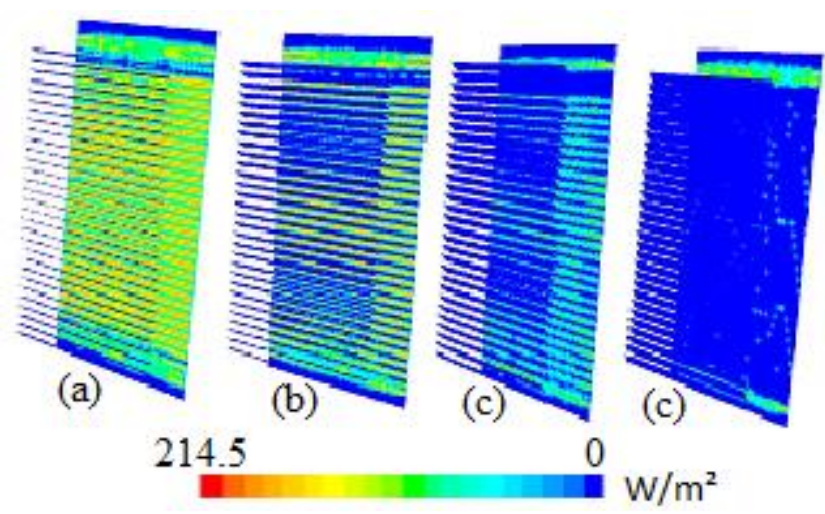

$(11 b)$

Figure 11: (a) Contour of solar heat flux at the surface of the internal glaze-1 and the blinds (b) contour of transmitted visible solar flux at the surface of the internal glaze- 1 and the blind.

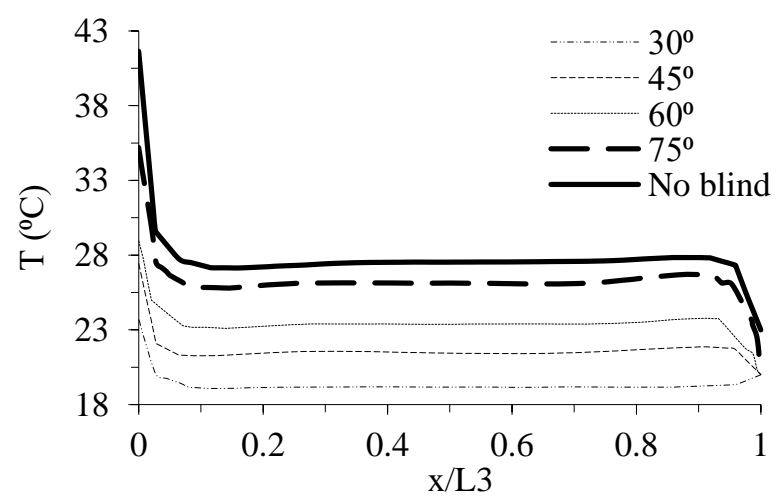

(12a) 


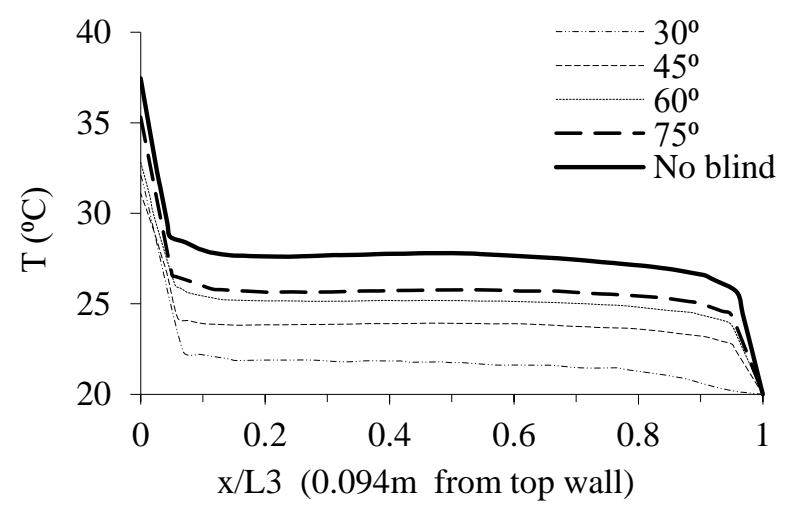

(12b)

Figure 12: Temperature profile at (a) mid-height of the indoor space (b) near the top wall (0.094 from top wall) of the indoor space

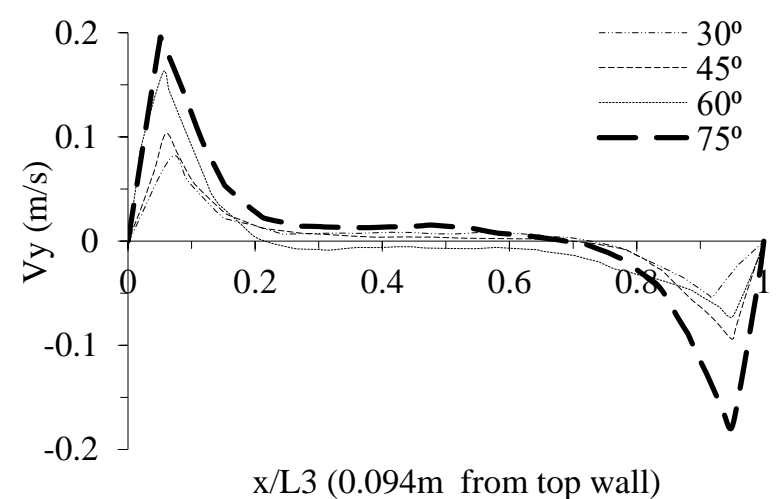

Figure 13: Velocity profile near the top wall of the indoor space

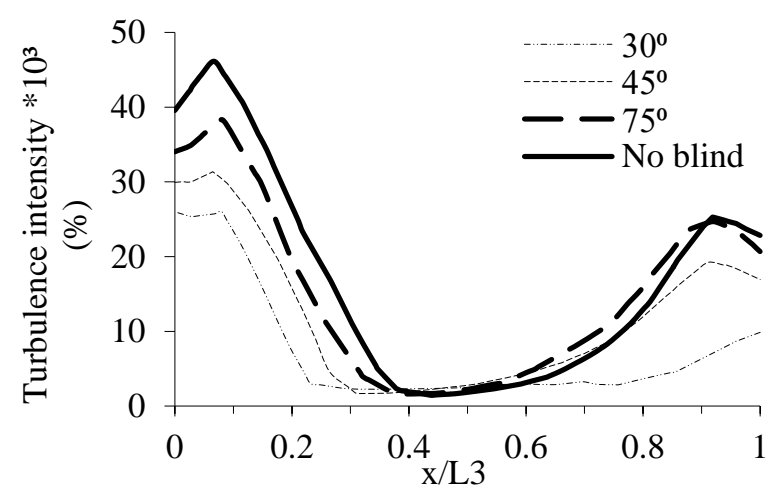

Figure 14: Turbulence intensity at mid-height of the indoor space

Table 8: Average parameters evaluated at internal glaze-2

\begin{tabular}{lllll}
\hline$\theta\left(^{\circ}\right)$ & $\begin{array}{l}\mathrm{T} \\
\left({ }^{\circ} \mathrm{C}\right)\end{array}$ & $\begin{array}{l}\mathrm{Q}_{\text {total }} \\
\left(\mathrm{W} / \mathrm{m}^{2}\right)\end{array}$ & $\begin{array}{l}\mathrm{Q}_{\text {solar }} \\
\left(\mathrm{w} / \mathrm{m}^{2}\right)\end{array}$ & $\begin{array}{l}\mathrm{Q}_{\text {transmitted }} \\
\text { visible solar } \\
\left(\mathrm{w} / \mathrm{m}^{2}\right)\end{array}$ \\
\hline 30 & 25.25 & 14.35 & 18.79 & 6.99 \\
45 & 28.28 & 16.95 & 23.22 & 29.80 \\
60 & 30.15 & 21.86 & 28.58 & 57.67 \\
75 & 33.51 & 26.67 & 34.80 & 89.80 \\
\hline
\end{tabular}




\begin{tabular}{|c|c|c|c|}
\hline No blind & 39.33 & 37.77 & 45.8 \\
\hline
\end{tabular}

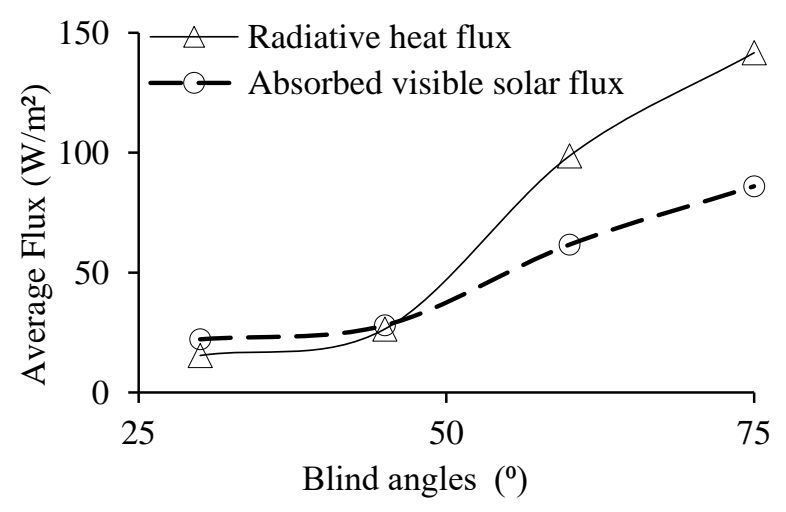

Figure 15: indoor wall average surface heat flux as a function of blind angle

There appears to be a direct relationship between incident solar irradiation transmitted to the indoor space and the inclination angles of the solar blockage as can be seen from Figs12a-b. As the solar blockage angle increases (opening), solar irradiance transmitted to the indoor space also increases. This behaviour is further evidenced in the plots of the flow velocity and turbulence intensity profiles as shown in Fig.13 and 14 respectively.

Figs.11a -b show contours of solar heat flux and transmitted visible solar flux for the surface of internal glazing- 1 and the blinds. The results demonstrate that there is a direct relationship between the blind inclination angles and the transmitted solar heat flux and the visible solar heat flux. The solar heat and visible solar fluxes transmitted are higher with increased solar blind angle; as a result, the radiative and convective gains to the indoor space are noticeably higher (Fig.15). Similar behaviour is also observed with the average temperature distribution at the internal glaze- 2 and the average heat flux of the internal glaze-2, average solar heat flux of the internal glaze surface and the transmitted visible solar heat flux (Table 8). The blind angle also affects the turbulence level of the indoor air as shown in Fig.14.

\section{Conclusion}

The need to fully describe the solar and thermal characteristics of complex glazing/blockages systems is critical for providing the necessary inputs into building energy simulations to assess the potential in energy saving. The correct behaviour of a DSF is the key to increasing energy savings and hence requires the structure to be carefully designed. In this study, detailed CFD results of a DSF system are presented. The current study complements previous study of Mei et al. [11] by addressing the detailed heat transfer due to the influence of numerical modelling strategies, influence of solar blockages inclination angle and proximity form the external facade and provides a comparative analysis of the net heat gain to the indoor environment and the relative magnitude of its components.

Sensitivity analysis for different numerical modelling strategies has been conducted for four different cases which include: channel, outdoor-channel, channel-indoor and then outdoor-channel-indoor fluid domains. It was observed that there is no significant difference in the quantification of the thermal behaviour for tested configuration. Therefore, it is recommended to model the DSF channel in isolation if the outdoor or indoor spaces are not key factors for the airflow and heat transfer. However, the outdoor and the indoor thermal boundary conditions must be well defined. 
The effects of the solar blockage inclination angles located in the DSF channel were analysed. Heat gain into the indoor space and its components are moderated by the solar blockages device. The solar blockages device within the cavity can be considered to separate the cavity into two vertical chambers, in front of and behind the blockages. It is concluded that the blockages have a significant influence on the thermal and airflow performance of the facade. If the solar blockage device is almost fully closed ( $30^{\circ}$ inclination), the 'front chamber' of the cavity and the blockage element itself will have higher temperatures than if it was opened. In contrast, the temperature behind the solar-blockage device will be higher if the solar-blockage device is almost fully opened ( $75^{\circ}$ inclination). The net heat gain to the indoor space is dominated by transmitted solar radiation, with a small contribution from the radiative and convective fluxes. This is the expected result with a non-shaded glazing which does little to block the solar radiation. With closing the solar blockages $\left(30^{\circ}\right)$, heat transfer to the building can be minimized to about $85 \%$ of the incoming solar energy.

In general, the net heat gain to the indoor environment can be reduced considerably with solar blockage devices (venetian blinds) in place. The energy efficiency of the DSFs can be enhanced by controlling the slat angle of the solar-blockage device. The optimum solar blockages position in terms of energy saving is $0.195 \mathrm{~m}$ where the heat transfer to the indoor space is minimum.

\section{References}

[1] K. C. Lin and A. Violi, "Natural convection heat transfer of nanofluids in a vertical cavity: Effects of non-uniform particle diameter and temperature on thermal conductivity," International Journal of Heat and Fluid Flow, vol. 31, pp. 236-245, Apr 2010.

[2] L. D. L. Mei L, Infield DG, Hanby V, Cook M, Li Y, Holmes M, Bates J., "The Influence of Blinds on Temperatures and Air Flows within Ventilated Double-Skin Facades," presented at the Proceedings of Clima 2007 Well Being Indoors.

[3] N. Safer, M. Woloszyn, and J. J. Roux, "Three-dimensional simulation with a CFD tool of the airflow phenomena in single floor double-skin facade equipped with a venetian blind," Solar Energy, vol. 79, pp. 193-203, 2005.

[4] P. Ye, S. J. Harrison, P. H. Oosthuizen, and D. Naylor, "Modelling of convective heat transfer from a window glass adjacent to a venetian blind," Heat Transfer 1998, Vol 3, pp. 195-200, 1998.

[5] W. Pasut and M. De Carli, "Evaluation of various CFD modelling strategies in predicting airflow and temperature in a naturally ventilated double skin facade," Applied Thermal Engineering, vol. 37, pp. 267-274, May 2012.

[6] M. W. Nassim Safer, Jean-Jacques R., Gilles R., and Frederic K, "Modelling of Double-Skin Facades for Building Energy Simulations: Radiative and Convective Heat Transfer," presented at the Ninth International IBPSA Conference, Montreal, Canada, August 15-18, 2005.

[7] R. Fuliotto, F. Cambuli, N. Mandas, N. Bacchin, G. Manara, and Q. Y. Chen, "Experimental and numerical analysis of heat transfer and airflow on an interactive building facade," Energy and Buildings, vol. 42, pp. 23-28, Jan 2010.

[8] Y.-X. T. Teshome E.J., and Fariborz H, "Airflow and heat transfer in double skin facades," Energy and Buildings, vol. 43, pp. 2760-2766, 2011.

[9] W. L. Wong N. H., Aida N. C., Anupama R. P., and Wei X, "Effects of double glazed facade on energy consumption, thermal comfort and condensation for a typical office building in Singapore," Energy and Buildings vol. 37, pp. 563-572, 2005. 
[10] a. J. A. Mona A., "CFD Modelling of a New Natural Ventilated Double Skin Facade Configuration in a Chicago High-Rise Office Building," presented at the Fourth National Conference of IBPSA-USA, New York, 2010.

[11] Y. Ji, M. J. Cook, V. I. Hanby, D. G. Infield, D. L. Loveday, and L. Mei, "CFD modelling of Double-Skin Facades with venetian blinds," Building Simulation 2007, Vols 1-3, Proceedings, pp. 1491-1498, 2007.

[12] H. K. Versteeg and W. Malalasekera, An introduction to computational fluid dynamics : the finite volume method, 2nd ed. Harlow, England; New York: Pearson Education Ltd., 2007.

[13] W. Chen and W. Liu, "Numerical and experimental analysis of convection heat transfer in passive solar heating room with greenhouse and heat storage," Solar Energy, vol. 76, pp. 623633, 2004.

[14] R. G. M. Hasan, J. J. McGuirk, D. D. Apsley, and M. A. Leschziner, "A turbulence model study of separated 3D jet/afterbody flow," Aeronautical Journal, vol. 108, pp. 1-14, Jan 2004.

[15] S. J. Wang and A. S. Mujumdar, "A comparative study of five low Reynolds number kepsilon models for impingement heat transfer," Applied Thermal Engineering, vol. 25, pp. 3144, Jan 2005.

[16] S. Chandrasekhar, Radiative transfer. New York,: Dover Publications, 1960.

[17] H. C. Hottel and A. F. Sarofim, Radiative transfer. New York,: McGraw-Hill, 1967.

[18] M. F. Modest, Radiative heat transfer, Third Edition. ed.

[19] R. F. WARD G., and CLEAR R., "A ray tracing solution for diffuse interreflection," Comp. Graphics, vol. 4, p. 8592, 1988.

[20] M. M., Radiation Heat Transfer, . New York: McGraw-Hill, 1993.

[21] I. C. a. B. Belgian Building Research Institute (BBRI) (2002). Source book for a better understanding of conceptual and operational aspects of active facades. Department of Building Physics.

[22] S. H. Jang and M. W. Shin, "Thermal analysis and modeling of led arrays for automotive headlamp," Proceedings of the Asme International Mechanical Engineering Congress and Exposition 2007, Vol 5, pp. 247-250, 2008. 